\title{
Organ donation in Korea in 2018 and an introduction of the Korea national organ donation system
}

\author{
Won-Hyun Cho \\ Korea Organ Donation Agency, Seoul, Korea
}

\begin{abstract}
A total of 1,503 solid organs were procured from 449 deceased donors in 2018. Although the number of donors was down by $12.8 \%$ from the previous year ( 8.7 per million population), the number of organs procured per donor increased from 3.29 in 2017 to 3.35 in 2018 . While the causes of brain death by cerebrovascular diseases and head trauma from traffic accidents have declined, brain damage from hypoxia has increased slightly. The most prominent change in the decline of organ donations was a decrease in family consent (36.5\% in 2018 vs. $42.9 \%$ in 2017). The disagreement over organ donations by other family members even extended beyond the next of kin, and the restriction of organ donations in connection with the suspension of end-of-life care partly affected the consent rate, making this a controversial social issue. An accurate analysis regarding the factors causing the decline of familial consent rates is required, and related organizations along with the government should make a unified concerted effort to resolve this issue. To help achieve this goal, this manuscript describes the transplantation process and briefly explains the Korean domestic organ donation system.
\end{abstract}

Keywords: Brain death; Organ donation; Organ procurement organization; End of life care

\section{INTRODUCTION}

According to United States transplantation statistics, the number of individuals awaiting transplants have decreased for the first time in 2016, and the annual number of organ donors have increased continuously in 2018, suggesting that the combined national effort to secure organ donors has been fruitful [1-3]. The international community also continues to actively encourage efforts through the Declaration of Istanbul Custodian Group in the long-term ethical self-sufficiency needed for transplantation for its own citizens since the 2008 Declaration of Istanbul [4,5]. Leading countries in transplantation are trying to increase

Received July 22, 2019

Revised November 12, 2019

Accepted November 16, 2019

Correspondence to: Won-Hyun Cho

Korea Organ Donation Agency, \#36, Choongjung-ro 133-gil, Seodaemun-gu, Seoul 03741, Korea

Tel: +82-2-542-5632, Fax: +82-2-3447-5631

E-mail:wh51cho@gmail.com the numbers of donors by increasing the referral rates, consent rates, procure rates, transplant rates, etc., from deceased donors, while actively implementing donations from expanded donor criteria or donors after circulatory death [6]. In the Korean transplantation system, there has been an increase in the number of deceased donors through continuous efforts, but unfortunately, the number has not recovered since its last decrease in 2017 (Table 1) [7]. This manuscript aims to evaluate the significance of the numbers in the 2018 Korea Organ Donation Agency (KODA) annual report and identify improvement strategies.

Prior to the analysis, it is important to note that there are difficulties in producing consistent reports on the current state of organ donations in Korea due to structural complexities that cannot be expressed by simple figures. For example, two organizations, KODA and the Hospital Organ Procurement Organization (HOPO), are responsible for the management of brain-dead patients.

This is an Open Access article distributed under the terms of the Creative Commons Attribution Non-Commercial License (http://creativecommons. org/ licenses/by-nc/4.0/) which permits unrestricted non-commercial use, distribution, and reproduction in any medium, provided the original work is properly cited. 


\section{HIGHLIGHTS}

- Increasing number of brain death due to hypoxic brain damage after cardiovascular accident and suspension of end of life care push us to prepare donation after circulatory death as soon as possible.

Potential brain deaths are collectively reported to KODA's call center, while the settlement of payment depends on the organization that is in charge of the patient.

Therefore, domestic donation statistics cannot be reported only by KODA's annual results, and it is difficult to consistently arrange comparisons between institutional achievements and business statistics. However, since domestic donation statistics are widely cited in foreign countries, it is necessary to summarize and analyze all the deceased donors that developed in 2018 regardless of donor managing hospital. This year's statistics on reported potential brain deaths, harvested organs from reported donors, and the transplant status of donated organs are based on the 2018 annual report of KODA and Korean Network for Organ Sharing (KONOS).

\section{KOREAN ORGAN DONATION STATISTICS FOR 2018}

In 2018, 3,908 organ transplants were performed in Korea, of which 1,503 were donations from the deceased and 2,405 were living donations.

\section{Potential Deceased Donors Reported to KODA and Their Management}

Potential brain deaths that occur in each hospital are to be reported to KONOS through KODA ("Act on organ transplantion" [AOT], Article 17) [8], yet the entire number of potential brain deaths in Korea has not been fully investigated. There are two types of medical institutions for identifying potential brain deaths. One is HOPO, an institution designated by the government to notify and assess potential deceased donors (AOT, Article 20) since 2003, and the second is the national in dependent organ procurement organization, comprised of hospitals contracted with KODA ("KODA hospitals"), that manage deceased donors abiding to the revised law of 2010 (AOT, Article 19). It is possible to estimate brain deaths in KODA hospitals through organ procurement coordinators (OPCs) who directly cooperate with the medical staff of each hospital in identifying potential brain deaths. However, in the case of HOPO, it is difficult to determine the exact number of occurrences of each hospital except for those cases that are reported to KODA.

Once potential brain deaths are reported to KODA, the OPC goes through a variety of steps ranging from assessment of medical suitability, family interviews and donation consent, brain death determination and management, and finally arrange the organ procurement team from every recipient hospital. In 2018, 2,426 potential brain deaths were filed at the KODA Call Center, of which 1,393 were medically suitable and had family

Table 1. Results of potential brain death donors reported to KODA (2014-2018)

\begin{tabular}{cccccc}
\hline Year & $\begin{array}{c}\text { PBD reported to } \\
\text { KODA referral center }\end{array}$ & $\begin{array}{c}\text { Medically } \\
\text { suitable PBD }\end{array}$ & $\begin{array}{c}\text { PBD possible to } \\
\text { family interview }\end{array}$ & $\begin{array}{c}\text { Agreed to organ } \\
\text { donation } \\
\text { (consent rate) }\end{array}$ & $\begin{array}{c}\text { Procure rate } \\
\text { (more than one organ } \\
\text { procured) }\end{array}$ \\
\hline 2014 & 1,615 & $1,171(72.5)^{\mathrm{a})}$ & $950(81.1)^{\mathrm{b})}$ & $517(54.4)^{\mathrm{c})}$ & $449(46.9)^{\mathrm{d})}$ \\
2015 & 1,850 & $1,344(72.6)$ & $1,068(79.5)$ & $552(51.7)$ & $501(46.9)$ \\
2016 & 2,083 & $1,538(73.8)$ & $1,237(80.4)$ & $652(52.7)$ & $573(46.3)$ \\
2017 & 2,216 & $1,692(76.4)$ & $1,348(79.7)$ & $578(42.9)$ & $515(38.2)$ \\
2018 & 2,426 & $1,833(75.6)$ & $1,393(75.9)$ & $509(36.5)$ & $449(32.2)$ \\
Total & 10,190 & $7,578(74.4)$ & $5,996(79.1)$ & $2,808(46.8)$ & $2,484(41.4)$ \\
\hline
\end{tabular}

Values are presented as number (\%).

KODA, Korea Organ Donation Agency; PBD, potential brain death.

${ }^{a}$ Medically suitable donor/report to KODA; ${ }^{\text {b) }}$ Family interview/medical suitable; ${ }^{\text {c) }}$ Consent/family interview; ${ }^{\text {d) }}$ Procure/family interview. 
interviews. Among the possible interviewees, 509 (36.5\%) agreed with organ donations, and in 449 cases $(32.2 \%)$, one or more organs were procured from the deceased donor. The average number of organs procured from the deceased donors increased to 3.35 compared to 3.29 in 2017.

The number of potential brain deaths reported to KODA over the last five years has continued to increase, but that number has not been directly linked to the number of actual donors. In particular, despite the increase of reported potential brain deaths, the proportion of medically suitable patients declined in 2018 (Table 1). While it is clear that the awareness for reporting potential brain deaths had increased in each hospital, it is possible that the guidelines for reporting potential brain deaths have been misused or misinterpreted. This suggests that continued education for the medical staff is required.

\section{Consent Rate for Organ Donation and Procure Rate}

Unlike other countries, there are many cases in which OPCs cannot interview family members, even for potential brain deaths in KODA hospitals. Therefore, when calculating the donation consent rate, it is difficult to make an estimation based on medically suitable donors. Because of this, we defines the consent rate for organ donation on the base of guardian interview, not the medical availability. Organ procure rate also calculated by the proportion of donors more than one organ harvested among the family interviewed group. The consent rate was $36.5 \%$, down from $52.7 \%$ in 2016 and $42.9 \%$ in 2017. The organ procure rate also decreased from $46.3 \%$ in 2016 to $37.2 \%$ in 2017 , and $32.2 \%$ in 2018 (Table 1)

\section{Cascade of Potential Brain Death Management Cases of medically unsuitable donor}

When a potential brain death (AOT, Article 17; the Enforcement Rule, Article 11) is reported to the KODA Call Center from a hospital, the OPC reviews the medical records and clinical findings of brain death to determine if a donation is possible. In 2018, $24.4 \%$ of the reported 593 cases were determined to be unsuitable. Even without complex tests, the OPC can examines the prerequisites for brain death, such as the presence of irreversible organic brain lesion, absence of spontaneous breathing, unconsciousness, loss of brainstem reflexes, shock or and coma due to metabolic diseases or not, and hypothermic status, while assessing whether the possibility of a transplant is hampered by infectious diseases, history of cancer, systemic inflammatory conditions, or the presence of internal trauma (Fig. 1).

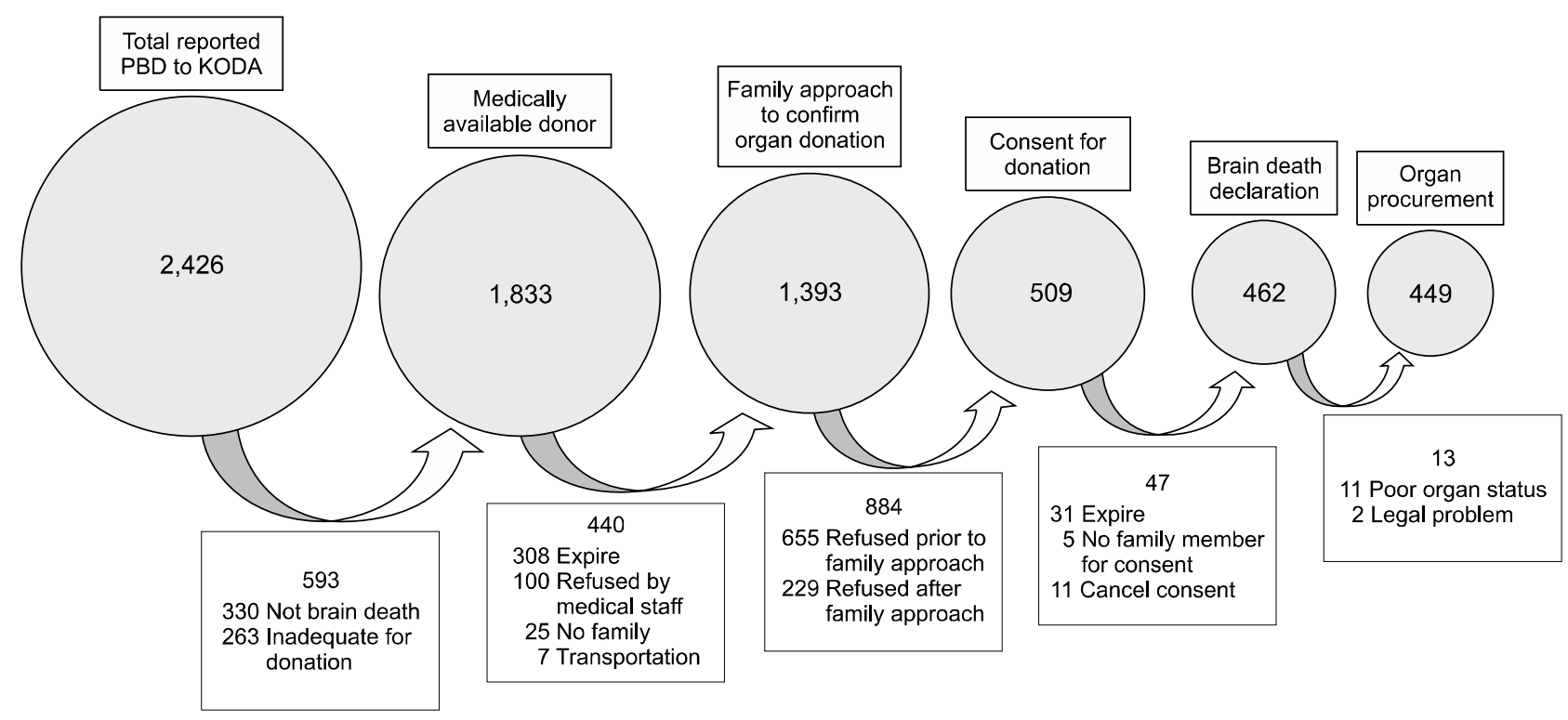

Fig. 1. Potential brain death (PBD) management cascade in 2018. KODA, Korea Organ Donation Agency. 


\section{Cases of unavailable family interviews}

Although the reported patients were available for organ donation, 440 cases were not possible to confirm the family's intentions because they could not be interviewed. Of these, 308 patients died, and in some cases, either a family member was not found or the patient was transferred to other institutions. If the AOT is revised and organ donations after circulatory death become possible, many types of patients who died during this period might become potential donors. Additionally, it has become increasingly difficult in recent years for KODA organ procurement coordinator (OPC) to meet the guardians or medical staff due to the restricted access for outside personnel, limited meeting hours, and limited work hours of the doctors. Therefore, a solution is required for such situations.

\section{Cases of donation refusal}

There were 884 cases of donation refusal out of the 1,393 cases where the family members were approached, resulting in a refusal rate of $63.5 \%$. Among those who refused, $655(74 \%)$ refused the interview itself when approached by a KODA OPC, and 229 (26\%) refused to donate after being informed of the donation process through the interview. Among those who rejected the interview, some had negative stereotypes about organ donation while others refused based on their fears about disconfiguration of their loved one after donation.

In $11.8 \%$ of total donation refusal cases, consent was given by a family member with the highest legal priority, but was reversed by another family member after their first de- cision (Table 2). This repetitive pattern suggests a need for a shift in social awareness to respect the person with the highest legal priority or the deceased' s donation intentions. It also shows that the consent of the person with the highest priority as defined by the law (AOT, Article 4, Article 12, and Article 22, Paragraph 3) is necessary, but not an absolute condition for donation. Foreign countries have already implemented systems in favor of first person or initial consent [9-11].

\section{Cases of failed organ procurement}

Among the 509 cases that acquired donation consent, 449

Table 3. Modified Maastricht classification of donations after circulatory death

\begin{tabular}{|c|c|}
\hline Category & Clinical status \\
\hline I (uncontrolled) & $\begin{array}{l}\text { Found dead: sudden unexpected cardiac arrest } \\
\text { without any attempt of resuscitation by a } \\
\text { life-medical team } \\
\text { IA: out of hospital } \\
\text { IB: in hospital }\end{array}$ \\
\hline II (uncontrolled) & $\begin{array}{l}\text { Witnessed cardiac arrest: sudden unexpected } \\
\text { irreversible cardiac arrest with unsuccessful } \\
\text { resuscitation } \\
\text { IIA: out of hospital } \\
\text { IIB: in hospital }\end{array}$ \\
\hline III (controlled) & Planned withdrawal of life-sustaining therapy \\
\hline IV (UC or C) & $\begin{array}{l}\text { Sudden cardiac arrest after diagnosis of brain } \\
\text { death }\end{array}$ \\
\hline $\mathrm{V}$ & $\begin{array}{l}\text { Medically assisted cardiac arrest and } \\
\text { subsequent organ donation in some country }\end{array}$ \\
\hline
\end{tabular}

UC, uncontrolled; C, controlled.

Table 2. Refused organ donations by other family member

\begin{tabular}{|c|c|c|c|c|c|}
\hline Year & PBD reported & $\begin{array}{c}\text { Medically } \\
\text { available PBD }\end{array}$ & $\begin{array}{l}\text { Total number of } \\
\text { refuse (1) }\end{array}$ & $\begin{array}{l}\text { Initially consented by } \\
\text { next of kin but refused } \\
\text { by other family (2) }\end{array}$ & $\begin{array}{l}\text { Rate of refusal by other } \\
\text { family member }(\%) \\
=(2) /(1)\end{array}$ \\
\hline 2013 & 1,446 & 872 & 371 & 81 & 21.83 \\
\hline 2014 & 1,615 & 901 & 432 & 57 & 13.19 \\
\hline 2015 & 1,850 & 1,122 & 515 & 60 & 11.65 \\
\hline 2016 & 2,083 & 1,272 & 585 & 64 & 10.94 \\
\hline 2017 & 2,216 & 1,380 & 770 & 74 & 9.61 \\
\hline 2018 & 2,426 & 1,440 & 888 & 105 & 11.82 \\
\hline
\end{tabular}

PBD, potential brain death.

Data from Korea Organ Donation Agency call center [7]. 
(88.2\%) reported successful organ harvesting and transplantation. The organs of the remaining 60 cases were not donated because of unexpected cardiac arrest (31 cases) before or after brain death determinations, owing to poor organ conditions (11 cases), or due to a medical examiner's request to investigate the cause of accident. Donors who developed cardiac arrest after the first or second brain death examination but not get the decision from the Brain Death Decision Committee, belong to Maastricht category 4 (Table 3), and this group can be proceeded to organ procurement under current law but is a matter of debate about lack of final decision from committee.

In Korea, one is lawfully determined to be dead (AOT, Article 18; the Enforcement Decree, Article 21) only after two thorough clinical examinations for brain death and confirmatory test, and a final decision by the Brain Death Decision Committee. Only then is the organ procurement surgery allowed to begin. The two examinations for brain death are conducted at least 6 hours apart (24 to 48 hours depending on the age for infants), and takes an average of 2-3 days, considering the time required for the Brain Death Decision Committee meeting. However, brain dead patients who are hemodynamically unstable can develop cardiac arrests at any moment during the determination process. Brain death determinations should be precise and accurate, but all staff should try to avoid unnecessary delays. Due to the recent limitation of working hours, brain death examination and committee work also possibly delayed which affect the fate of donor and result in failure to donate.

\section{Clinical Characteristics of Deceased Donors}

There were more deceased donors who were male $(70.4 \%)$ than female $(2.38: 1)$. This is higher than the male to female ratio of living donors (1.04:1), and higher than the proportion of male donors, $60 \%(59 \%-60 \%)$ in the United States. It is also interesting that this ratio is higher than the sex ratio of all deaths in Korea (1.18:1) $[1,12,13]$.

In Korea, there have always been more male donors, alive or deceased, except for the living donors of kidneys in which female donors have a higher ratio (1.35:1).
Meanwhile, the number of male recipients was higher for both donors that were alive (1.94:1) and deceased (1.81:1)

The age of donors has increased during the past 5 years and the average exceeded 50 for the first time last year (average, 52.5 years). The youngest donor was 74 days old and the oldest was 81 years of age. Donor aging is a natural result as the percentage of deaths for both men and women have reached $75 \%-80 \%$ for those over 60 years of age according to the national death toll statistics [12]. Therefore, the policy for the distribution of the organs if the donor's organs have declined in physiological function due to their age needs to be advanced [3], and the optimal organ distribution policy for the steadily increasing expanded criteria donors also needs to be discussed [14,15].

Brain deaths due to cerebrovascular disease have decreased while brain deaths due to hypoxia (cardiac arrest

Table 4. Characteristics of brain death donors

\begin{tabular}{lc}
\multicolumn{1}{c}{ Characteristics } & Value \\
\hline Sex & \\
Male & $316(70.4)$ \\
Female & $133(29.6)$ \\
Age (yr) & $52.5(74-81)$ \\
Blood type (\%) & \\
Type A & 31.4 \\
Type B & 26.7 \\
Type AB & 27.4 \\
Cause of brain death & $159(35.4)$ \\
Cerebrovascular disease & $164(36.5)$ \\
Hypoxic brain injury & $120(26.7)$ \\
Head trauma & $128(28.5)$ \\
Type of brain death & $321(71.5)$ \\
Traumatic & \\
Nontraumatic & 8.09 \\
No. of donors according to city type (pmp) & 9.17 \\
Metropolitan city ${ }^{\text {a) }}$ & \\
Other local government ${ }^{\text {b) }}$ & 32.7 \\
No. of recipients according to city type (pmp) & 26.3 \\
Metropolitan city & \\
Other local government & \\
\hline \hline
\end{tabular}

Values are presented as number $(\%)$ or average (range) pmp, per million population.

${ }^{a)}$ Metropolitan city including Seoul, Busan, Daegu, Daejeon, Gwangju, Incheon, Ulsan; b) Other local government including Gyeonggi, Ganwon, Chungbuk, Chungnam, Jeonbuk, Jeonnam, Gyeongbuk, Gyeongnam, Jeju. 
due to cardiovascular disease, brain damage due to suffocation) have increased. According to Korean statistics, the death rate from car accidents has continuously decreased by $35.6 \%$ compared to 10 years ago, and the death rate from cerebrovascular disease per 100,000 population has decreased from 64.1 in 2005 to 48.0 in 2015 [12]. Therefore, the organ procurement policy needs to be modified according to the changes in the causative diseases of brain death. Organ donation activities have been conducted mainly through potential braindead patients, but with deaths due to hypoxic brain damage after cardiovascular accident and suspension of end of life care increasing, donation after circulatory death will become another main source of deceased donor in Korea (Tables 4 and 5) [16,17].

The number of deceased donors and transplant recipients were compared by city size (Table 4. metropolitan vs other local government). The number of donors was higher in other local governments (8.09 vs. 9.17 per million population [pmp]), while the number of transplant recipients was much higher in Seoul and metropolitan cities (32.7 vs. $26.3 \mathrm{pmp}$ ). The meaning of this difference is that there are more heart, lung, pancreatic, and liver transplants in the medical institutions of metropolitan cities and Seoul.

\section{Transplantation Status of Donated Organs}

A total of 1,528 organs were extracted from a total of 449 deceased donors, of which 1,503 were transplanted into end stage organ failure patients. Among 1,528 procured organs, $12(0.8 \%)$ were not transplanted due to various reasons but the discard rate of Korea was far less than that of United State (Table 6). The reason for this difference is the legal prohibition of organ procurement

Table 6. Produced organ and transplanted organ

\begin{tabular}{lrrc}
\hline \multicolumn{1}{c}{ Organ } & Procured organ & $\begin{array}{c}\text { Transplanted } \\
\text { organ }\end{array}$ & $\begin{array}{c}\text { Procured but } \\
\text { not transplanted }\end{array}$ \\
\hline $\begin{array}{l}\text { Heart } \\
\text { Lung }\end{array}$ & 176 & 176 & 0 \\
$\quad$ Bilateral & 90 & 88 & 2 \\
$\quad$ Unilateral & 2 & 4 & \\
Liver & & & \\
$\quad$ Whole liver & 356 & 356 & 0 \\
$\quad$ Split liver & 14 & 13 & 1 \\
Kidney & & & 6 \\
$\quad$ Right & 409 & 391 & \\
$\quad$ Left & 419 & 401 & \\
$\quad$ En-bloc & 0 & 15 & \\
Intestine & 1 & 1 & 0 \\
Pancreas & 59 & 58 & 1 \\
Pancreas islet cell & 2 & 0 & 2 \\
Total & 1,528 & 1,503 & 12 \\
\hline
\end{tabular}

Data from annual report of Korean Network for Organ Sharing, 2018 [18].

Table 5. Possibility of organ donation from end of life care suspended patients

\begin{tabular}{cccccc}
$\begin{array}{c}\text { Notification to refer } \\
\text { center of KODA } \\
(2018.2-2018.12)\end{array}$ & $\begin{array}{c}\text { Family want to suspend } \\
\text { end of life care } \\
\text { (want to suspend/ } \\
\text { total notification) }\end{array}$ & $\begin{array}{c}\text { Medically suitable } \\
\text { for donation } \\
\text { (suitable/want } \\
\text { suspension) }\end{array}$ & $\begin{array}{c}\text { Approach to family for } \\
\text { consent } \\
\text { (approached/suitable) }\end{array}$ & $\begin{array}{c}\text { Donation consented and procured organ } \\
\text { Consented donor } \\
\text { (consent/approached) }\end{array}$ & Procured donor \\
\hline 2,426 & $\begin{array}{l}\text { Want to 193(8.0) } \\
\text { suspend } \\
\text { end of life } \\
\text { care } \\
\text { No mention 2,233(92.0) } \\
\text { about } \\
\text { suspension }\end{array}$ & $156(80.8) 155$ & $127(81.4)$ & $16(12.6)$ & \\
\hline
\end{tabular}

Values are presented as number $(\%)$. 
without a designated recipient in Korea (AOT, Article 11, Paragraph 2). Foreign countries allow the extraction of organs as long as consent has been acquired, and some organs are on the machine perfusion until the best allocation is designated. Recently in the United States, a change in this policy has been discussed due to the increasing number of discarded kidneys extracted from elderly donors aged 65 years or older, diabetic donors, and donors with Kidney Donor Profile Indices $>85 \%$. In particular, the number of discarded kidneys among biopsied kidneys has been very high [1,3].

\section{Patients Awaiting Organ Transplantation and Average Waiting Period}

The waiting period of the potential recipients registrants on waiting list and those of actual recipients listed in KONOS annual statistics are all limited to the transplants available from deceased donors of brain death. According to the statistics, the waiting period of actual recipients varied according to each organ, such as 1,955 days for a kidney, 155 days for a liver, and 234 days for a heart. In the case of livers, the waiting period has been reduced which is estimated to have occurred after the change of liver emergency assessment standards into model for end-stage liver disease (MELD) scores in 2016 [13]. However, the average waiting periods of registrants on waiting list that had not yet received a transplant (as of May 31, 2018) were 1,592 days for a kidney, 1,934 days for a liver, and 1,347 days for a heart. The liver in particular showed the biggest difference between the waiting period of the actual recipients and registrants on waiting list. The reason for this, along with the relatively short waiting period, is because re-transplantation of the liver is of the highest priority in organ allocation, and a new registration number is given at the time of retransplantation determination (Table 7) [18].

It has actually been reported that the waiting period is influenced by the principles of organ allocation. Based on the analysis of waiting periods for deceased donor kidney allocations in Korea by Lee et al. [19], a relatively shorter waiting period was reported for recipients who received kidneys assigned to HOPO than general recipients. Considering the ethical allocation of the organs, such results signify the need for a revised general policy. The active waiting list can be determined by totaling the number counted at the beginning of the year, added with new registrants, and subtracting removed registrants, such as patients who received transplants, patients who are deceased or refused the transplant, patients whose health progress made the transplantation unnecessary, or patients whose bodies were too weak to receive a transplant $[1,13]$. Yet, depending on the patient's condition, the ones who cannot receive transplantation or the ones refusing transplantation are sometimes placed on an inactive waiting list rather than permanently removing them from the list. Nevertheless, our domestic reports of registrants on waiting list counted simply after exclusion of transplanted recipients, expired patient on waiting, voluntary cancellations, and those missing test values.

Table 7. Waiting time for transplant recipients each year and waiting lists

\begin{tabular}{lrrrrr}
\hline \multirow{2}{*}{ Organ } & \multicolumn{2}{c}{ Waiting time of transplanted recipient from deceased donor in each year ${ }^{\mathrm{a})}($ day) } & $\begin{array}{c}\text { Waiting time of registrant } \\
\text { at }\end{array}$ \\
\cline { 2 - 6 } end of May 2018
\end{tabular}

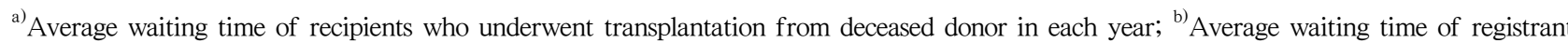
who are waiting for deceased donor transplantation at the end of May, 2018.

Data from annual report of Korean Network for Organ Sharing, 2018 [18]. 
Efforts to Increase the Expertise and Efficiency of Deceased Donor Management

Number of deceased donor according to donor management hospitals (KODA hospitals vs. HOPO hospitals)

There are 63 KODA hospitals (including eight HOPO hospitals) nationwide, and the number of brain deaths managed by these hospitals continues to increase every year, with 226 (50.3\%) out of 449 brain death managements in 2018. The increase in brain death managements is due to the increased number of KODA hospitals, and because management is held at the hospital that initially reported its occurrence, rather than transferring the patients to HOPO hospitals as has been the case in the past (Table 8). KODA hospitals had higher rates of brain deaths that occurred in their own hospitals (209 cases, 92.5\%) than HOPO hospitals (173 cases, 77.6\%). The low incidence rate for HOPO hospitals requires a careful analysis on whether their inpatient composition was different from those in KODA hospitals.

\section{Donor transfer for management of potential brain deaths}

One of KODA's major goals is to manage potential brain deaths without having to transfer the patients to other medical institutions for the sake of efficiency and professional care. This attempts to minimize the possibility of emergency situations, such as the death of a hemodynamically unstable and potentially brain-dead patient, and to reduce the tendency of donation withdrawals made by family members when transporting patients to another hospital. Within the three branches of KODA, transfers to other hospitals declined from $32.5 \%$ in 2014 to $14.9 \%$ in 2018, which is believed to be a result of KODA's efforts to manage the potential brain deaths within the hospital of occurrence (Table 8).

\section{POLICIES EXPECTED FROM FUTURE REVISIONS}

\section{Organ Donations from Patients Withdrawing Life Sustaining Treatment}

In 2018, when the "Act on Decisions on Life-Sustaining Treatment for Patients in Hospice and Palliative Care or at the End of Life" [20] was implemented, 2,426 potential brain deaths were reported to the KODA Call Center and 193 families (8\% of total reported cases) requested withdrawal of life sustaining treatments. Among these patients, 156 patients were eligible for brain death certification and medically suitable for donation, while the remaining 37 patients were unsuitable for organ donation. Of the 156 cases where donation was medically possible, 127 cases $(81.7 \%)$ reached the family interview stage, but only 16 cases obtained documentation for (12.6\% of the interviewees) donation consent. Compared to the group who did not wish to withdraw life sustaining treatments (2,233 cases), the donation consent rate was much lower (12.6\% vs. $38.9 \%)$ in the group that decided to withdraw life sustaining treatments. This is considered to have been affected by the withdrawal, which had al-

Table 8. Relationship between brain-dead donor identifications and management according to the donor management hospital

\begin{tabular}{|c|c|c|c|c|c|c|c|c|c|c|}
\hline \multirow{2}{*}{$\begin{array}{l}\text { Donor man- } \\
\text { aging hospi- } \\
\text { tal }\end{array}$} & \multicolumn{2}{|c|}{2014} & \multicolumn{2}{|c|}{2015} & \multicolumn{2}{|c|}{2016} & \multicolumn{2}{|c|}{2017} & \multicolumn{2}{|c|}{2018} \\
\hline & $\begin{array}{c}\text { Local } \\
\text { donor }^{\text {a) }}\end{array}$ & $\begin{array}{l}\text { Transpor- } \\
\text { ted donor }\end{array}$ & $\begin{array}{c}\text { Local } \\
\text { donor }^{a}\end{array}$ & $\begin{array}{l}\text { Transpor- } \\
\text { ted donor }\end{array}$ & $\begin{array}{c}\text { Local } \\
\text { donor }^{\text {a) }}\end{array}$ & $\begin{array}{l}\text { Transpor- } \\
\text { ted donor }\end{array}$ & $\begin{array}{c}\text { Local } \\
\text { donor }^{a}\end{array}$ & $\begin{array}{l}\text { Transpor- } \\
\text { ted donor }\end{array}$ & $\begin{array}{c}\text { Local } \\
\text { donor }^{\text {a) }}\end{array}$ & $\begin{array}{l}\text { Transpor- } \\
\text { ted donor }\end{array}$ \\
\hline $\mathrm{KODA}^{\mathrm{c})}$ & 107 & $6(5.3)$ & 161 & $4(2.4)$ & 195 & $15(7.1)$ & 196 & $18(8.4)$ & 209 & $17(7.5)$ \\
\hline $\mathrm{HOPO}^{\mathrm{d})}$ & 194 & $139(41.7)$ & 204 & $132(39.3)$ & 242 & $121(33.3)$ & 215 & $86(28.6)$ & 173 & $50(22.4)$ \\
\hline Total & $301(67.5)$ & $145(32.5)$ & 365 & $136(27.1)$ & 437 & $136(23.7)$ & 411 & $104(20.2)$ & 382 & $67(14.9)$ \\
\hline
\end{tabular}

Values are presented as number $(\%)$.

KODA, Korea Organ Donation Agency; HOPO, Hospital Organ Procurement Organization.

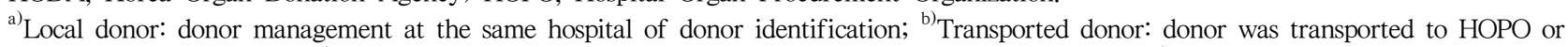
KODA contracted hospital; ${ }^{\text {c) }}$ Identified potential donor is managed at hospital contracted with KODA; ${ }^{\text {d) }} \mathrm{HOPO}$ : Identified donor is managed at HOPO hospital. 
ready been decided before considering an organ donation (Table 5).

Presently, the Korean laws concerning organ donation after circulatory deaths in Maastricht categories 3 or 4 are unclear. Nevertheless, due to the implementation of "Act on Decisions on Life-Sustaining Treatment for Patients in Hospice and Palliative Care or at the End of Life," there is an urgent need for legal and institutional amendments that will allow the donation of organs or tissues to be carried out after withdrawing life sustaining treatments. In fact, in the last two decades, European countries have rapidly increased donations after circulatory death to the point that it has reached latory death to the point that it has reached $20 \%-40 \%$ of the total number of deceased donors (brain deaths and circulatory death). In Spain, Belgium, the United Kingdom and the Netherlands, the number of donors after circulatory deaths reached more than 9.0 donors pmp [6]. This means that countries around the world are increasing organ donations from circulatory death donors. Donations after circulatory death have been attempted since the early 1900s, but due to inadequate medical knowledge at the time, the results were unsatisfactory, which led to donations from patients who were legally brain-dead. Recent advances in surgical techniques, long-term storage by perfusion machine, and the development of drugs have led to its re-emergence since 2000 [21-24]. Yet, removing life sustaining measures or decreasing warm ischemic times and inserting perfusion cannulas for organ procurement, injecting anticoagulants, etc., can collide with ethical and legal problems such as the "Dead Donor
Rule," making donations after circulatory death difficult despite current medical developments [25]. However, since many countries including Korea have recently implemented the "Act on Decisions on Life-Sustaining Treatment for Patients in Hospice and Palliative Care or at the End of Life," and allow for the removal of life sustaining measures, donations after circulatory deaths are expected to be permissible. In order to resolve the long-term shortage of domestic organ donations with donations following circulatory deaths, a partial revision of existing laws and systems is required (Fig. 2).

\section{First Person Authorization Legislation or Donor Designation}

First person authorization legislation refers to the organ procurement organization's expectation that the family of the deceased will honor the donor's voluntary organ donation and proceed with the donation process, when the willingness to donate one's organs is recorded on a driver's license, donor card, or legally valid document. This is a way to inform the family of the donor's decision instead of asking the family whether or not they wish honor the donor's wishes. This has been implemented in all 50 states in the United States, Australia, and in Europe. Family members' wishes are expected to have a lesser impact compared to the presumed consent law or the OPT OUT system. Additionally, families tend to respect the deceased's donation registration and participate more positively in the donation process. In addition, $65.7 \%$ of families were aware of the donation registration of the deceased, which implies that they had already discussed

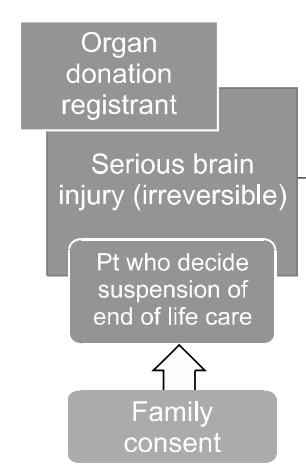

Pt under respirator

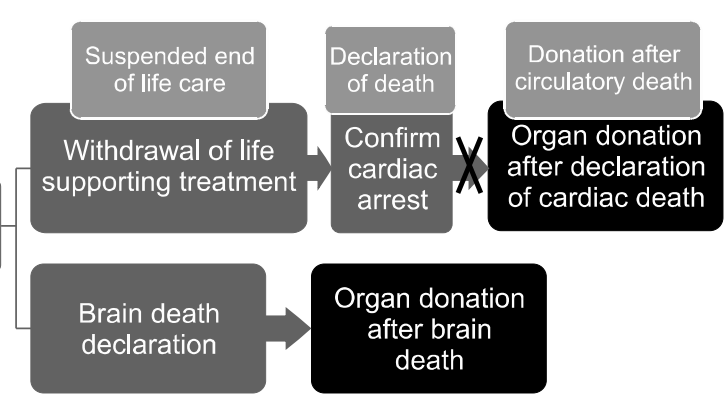

$\mathbf{X}$ : Block of organ donation opportunity currently
Fig. 2. Relationship of suspended end-of-life care and organ donations after circulatory death. Pt, patient. 
it with their families at the time of registration. In order for Korean society to adopt this concept and to make it more meaningful, there needs to be a significant increase in the number or donation registrants and an active campaign informing family members about the registration.

\section{Respect Towards the Person with the Highest Legal Priority}

AOT, Article 12, Paragraph 1, mentions that donations can proceed with the consent of a family member with the highest legal priority. In Article 4, Paragraph 6, of the same Act, the terms "family member" or "surviving family member" fall to the categories of spouse, lineal descendants, lineal ascendants, siblings, or first cousins if the donor has none of the family members listed above. Furthermore, according to Article 22, Paragraph 3 of the same Act, organs may be procured if the donor gave consent prior to brain death or if the donor' $\mathrm{s}$ family members or surviving members give consent. In practice; however, organ extraction cannot be forced when other family members do not agree with the consent given by the person with the highest legal priority (AOT, Article 22, Paragraph 3, Subparagraph 1). Even in $2018,11.8 \%$ of all refused donations were due to disagreements among family members and this situation occurs every year at a rate of approximately $10 \%$ (Table 2). Once the first person authorization passes legislation, then the respect towards the person with the highest legal priority is expected to also increase.

\section{SUMMARY OF INSTITUTIONS AND TASKS RELATED TO ORGAN DONATIONS AND TRANSPLANTATIONS}

After the AOT (enacted in 2000) was revised in 2010, various institutions and systems were already in place, but many new members in these organizations began their fieldwork without understanding its history. This has led to misunderstandings and unnecessary conflicts between institutions and staff. In order to help organize and understand the current progress, the following section summarizes all the processes related to organ donation.

\section{Institutions Related to Organ Donation and Transplants}

KONOS operates five life-sharing related organizations. These are the organ transplant registration organizations, organ transplant medical institutions, medical institutions determining brain death, the organ procurement organization, and HOPO.

\section{Organ procurement organization}

This organization is in accordance with the AOT, (Article 20) revised in 2010, and "Safety, Management of human tissue act" (Article 16). This is an independent organ procurement organization that receives reports of brain deaths or directly identifies them, manages the entire donation process after the family's consent for donation until procurement of organs, and connects it to a KONOS designated recipient hospital. Unlike HOPO, it is not affiliated to any hospital and the task is currently assigned to the KODA by the Ministry of Health and Welfare.

\section{HOPO}

The center for Korean Network for Organ Sharing is regulated by law to designate a $\mathrm{HOPO}$ to conduct the organ donations, brain death determinations, organ procurement, and transplantations from deceased donor (AOT, Article 19). HOPOs have been designated by the Ministry of Health and Welfare since 2003 after the enactment of the AOT in 2000, and also by Article 19 of the 2010 revision. In order to be designated as a HOPO, a facility must be equipped with the facilities and personnel according to Article 15, Paragraph 1, of the "Enforcement Rule of the AOT" and must submit an "Organ transplant registration organization designation letter," a "Brain death medical institution notification letter," and an "Organ transplant medical institution designation letter" to the head of KONOS. There are currently 36 HOPOs in Korea.

\section{KODA hospitals}

KODA hospitals are medical institutions contracted with KODA to identify brain deaths and effectively manage them. These institutions can manage the deceased donors even if they are not organ transplant hospitals according to Article 25, Paragraph 3 of the AOT and Article 22 of 
the Enforcement Rule. If a brain death occurs, a KODA procurement coordinator is dispatched to manage the potential donor with the medical staff of the hospital. Forty-six medical institutions nationwide have signed a brain death management agreement with HOPO to manage brain-dead patients, and eight out of 36 HOPO hospitals have signed a brain death management agreement with KODA and are managed by KODA OPCs.

\section{Specialized immunology laboratories for organ dona- tion and transplantation}

\section{KODA clinics}

A clinic that specializes in analyses such as immunological tests, cross-tests, blood type tests, and infection marker tests between the donors and beneficiaries for organ transplantation, and stores the specimens when a donor occurs at a KODA hospital (AOT, Article 20, Paragraph 7, the Enforcement Decree, Article 24) (Table 3).

\section{HOPO immunology laboratories}

The 19 immunology laboratories among the 36 HOPO hospitals, which store the serum of transplant recipients to conduct cross-tests, etc., for donation from deceased donors from the current HOPO hospital or a HOPO hospital that does not store sera.

\section{Organ transplant management organization}

KONOS receives the information of a brain-dead donor from KODA and matches that information with the nationwide transplant waiting list and selects the most appropriate and urgent transplant target. Currently, KONOS is in charge of organ allocation. In addition, it is responsible for registration of the transplant waiting list, statistics on donor and transplant recipients, promotion of organ donation and campaign, the supervision of organ transplant registration organizations (AOT, Article 13), medical institutions determining brain deaths (AOT, Article 16), HOPOs (AOT, Article 19), organ procurement organizations (AOT, Article 20), and organ transplant medical institutions (AOT, Article 25).

\section{Organ transplant medical institution}

An organ transplant medical institution is a medical institution that has the facilities, equipment, and personnel according to presidential decree, and is designated by the Minister of Health and Welfare to procure or transplant organs. If an institution is not a transplant medical institution, organs cannot be procured and transplanted. However, even in medical institutions other than transplant medical institutions, organs can be procured if they have the facilities, equipment, and personnel decreed by an Ordinance of the Ministry of Health and Welfare. Currently, there are some KODA hospitals that identify and manage brain-dead patients, but are not transplant medical institutions. The organ extractions of the brain-dead patients in these medical institutions are carried out in accordance with Article 25 of the AOT and Article 22 of the Enforcement Rule.

\section{Organ Donation Process from Identification of Potential Brain Death to Organ Procurement}

The most important aspect of the organ donation process is for the donor (or the family) to share the virtues of life sharing, respect, love, and sacrifice to make the donation successful. Therefore, no one involved in this entire process should cause the donor's will to be compromised by his or her carelessness, insincerity, or incompetence. Since the organ donation process, ranging from the occurrence, assessment, consent of donation, management, and extractions from deceased donors is complicated and involves various individuals from different practices (Fig. 3); it requires mutual understanding and respect of in order to protect the honorable will of the donor. Unlike other countries, an understanding of the domestic situation, where the donor's family waits in front of the operating room during organ procurement, is required. Therefore, it is important for hospital personnel to consider the family's feelings and reactions when they are met after the donor surgery, and during the organ transfer. Due to this complex and difficult process, organ procurement nurses are required to participate as an OPC under the law (the Enforcement Decree of the AOT, Article 23) (Table 2) to coordinate and facilitate these tasks. 


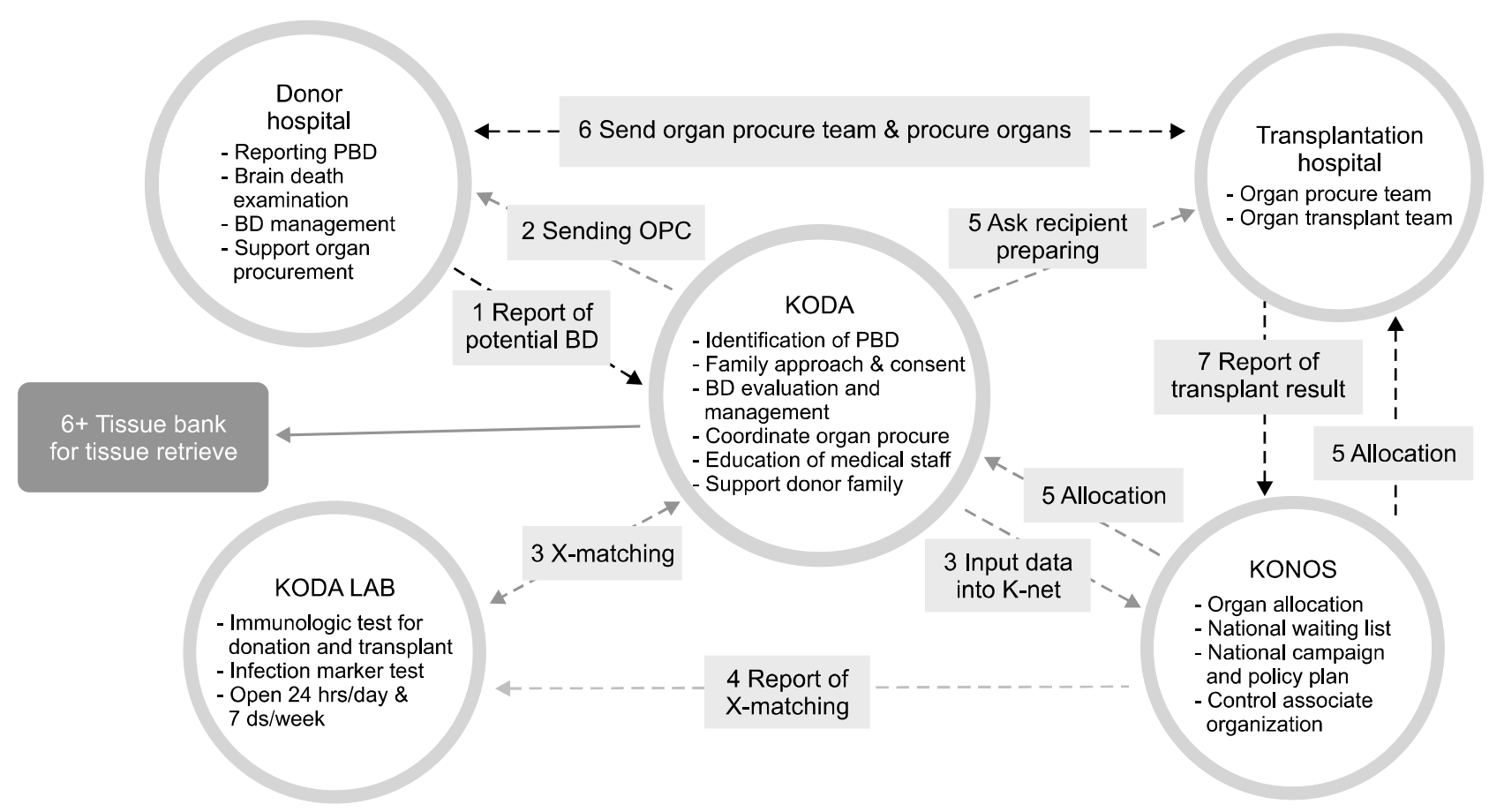

Fig. 3. Flowchart of potential brain death until organ procurement. PBD, potential brain death; OPC, organ procurement coordinator; KODA, Korea Organ Donation Agency; KONOS, Korean Network for Organ Sharing.

In order to facilitate the donation, individuals, transplant medical institutions, administrative self-governing centers, and even the police and prosecutors, in case of an accident, must give priority to their agency's own work and should not interfere with the flow of the entire process. In the case of the medical staff, all tests, the assembly of committees, and surgical plans for the management, and the determination of brain death must be carried out before the donor's heart stops, making cooperation between the medical staff and medical institutions crucial. The occasional case where the donor surgery time is arbitrarily modified, or another procurement team is kept waiting must not happen during the donation process. Moreover, the medical staff's ability and experience in organ procurement can either help or hinder the donor's willingness to donate and save even more patients. To this end, we also needs to verify the qualifications of the donor surgery teams dispatched for organ harvest, and this must be regulated autonomously. The conventional process for the organ donation of deceased donors is as follows: (1) Report or discovery of potential brain deaths: the hospital where the potential brain death occurred, reports to KODA, or a KODA organ procurement nurse discovers a potential brain death during the visit to each hospital. (2) Dispatch a KODA organ procurement nurse: if a potential brain death is reported, KODA will dispatch an organ procurement nurse to conduct a medical assessment and check if there are intentions for a donation. (3) Family consent and initiation of brain death determination: if the family agrees to donate, the determination of brain death will begin, the donor's medical information is registered to $\mathrm{K}-$ net, and immunology tests regarding donation are requested [3]. (4) Transplant recipient selection: KONOS selects the recipient for each organ after receiving the results from the KODA laboratories. (5) Announcement of selected recipients and preparing the donor surgery: the selected recipient is announced to the hospital and the KODA coordinator assembles the donor surgery team for each organ and establishes the date of surgery. (6) Organ (and tissue) procurement and transplant surgery: the organ procurement team of the notified transplant medical institution will be sent to the donor's hospital to harvest the organs and perform the transplant surgery (after fin- 
ishing the donor surgery, surgical wound repaired carefully and the body transported to the mortuary and return to donor family courteously. Donors that have agreed to tissue donation are transferred to the tissue bank's tissue collection team after organ procurement). After reporting the donation details, the donation process will be terminated. (7) Report: each transplant medical institution reports the results of the organ transplant surgery to KONOS.

\section{Cash Flow after Deceased Organ Donation Process}

In the past, the expenses associated with organ donation and transplantation were settled by HOPO or KODA, which were responsible for the management of brain-dead donors by receiving a certain amount of organ fee from the beneficiary for each organ. Starting on July 1, 2017, a new donor management fee was established by Korea's Health Insurance Review and Assessment Service (relative value score, 36,776.26; Korean Won 2.75 million for a unit price of 74.9 won per relative value score in 2019), of which the beneficiary pays $10 \%$ of the fee and the remainder is paid by health insurance (Fig. 4).

Article 42 of the AOT states that the costs incurred during organ extraction and transplantation shall be paid by the beneficiary, and the detailed costs shall be determined in accordance with the National Health Insurance Act. In addition, expenses not provided for in the National Health Insurance Act shall be stipulated according to the Ordinance of the Ministry of Health and Welfare. Therefore, the expenses for extracting and transplanting are calculated according to the noncovered medical expenses posted by the founder of a medical institution in accordance with Article 45, Paragraph 1 of the Medical Service Act.

The basic principle is that hospitals that manage deceased donors (HOPO) or KODA charges the management fee for brain-dead organ donors by the number of transplant patients at each beneficiary's hospital. The beneficiary hospital requests the Health Insurance Review and Assessment Service to charge the deceased donor's management fee in the name of the beneficiary and receive the claim from the National Health Insurance Service. Subsequently, the beneficiary hospital pays the management fee to HOPO or KODA, which includes the insurer's copayment and the beneficiary's out-of-pocket expenses. The copayment of each beneficiary will be collected and paid by KODA or HOPO hospitals in accordance with the expenses specified by the hospitals and other institutions (such as the laboratories) where the

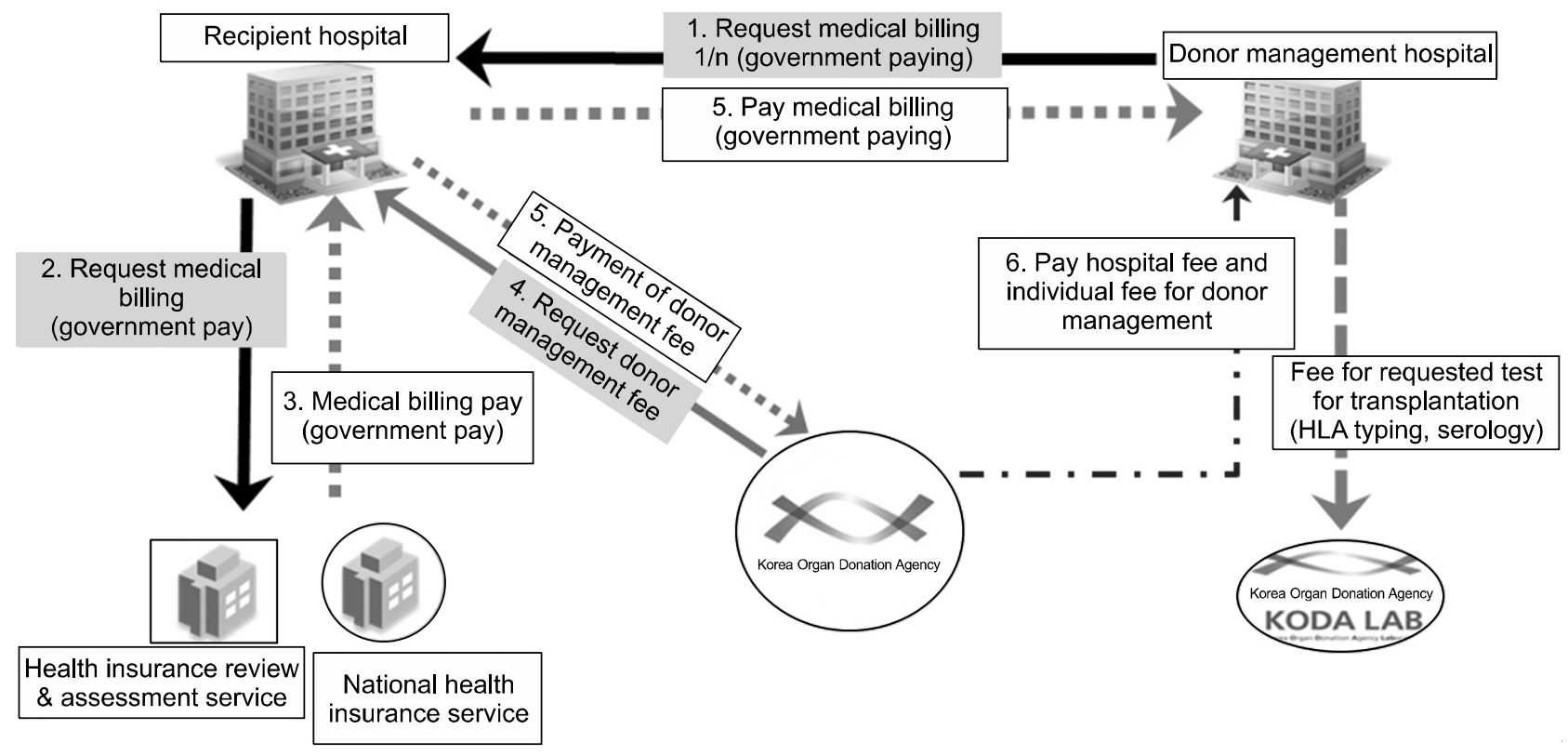

Fig. 4. Cash flow after donor management. HLA, human leukocyte antigen; KODA, Korea Organ Donation Agency. 
brain death occurred and where it was managed. This includes all direct and indirect costs from the date of consent to donation including organ donation and extraction, and is calculated for all costs incurred during the management and determination of brain death such as costs for examination, labor, consumables, surgery, operating room fees, hospitalization and anesthesia fees, donation counseling, loss compensation, and transportation.

\section{Donor Courtesy and Family Support Program}

The most important courtesy of life sharing is the appreciation of the beneficiaries and the whole country for the donors who gave their lives. Since life sharing is not performed with the promise of a reward, the greatest possible respect given to the donors is for all participating medical staff to fulfill the wishes of the donor and to provide emotional support to the donor's family providing the family with a sense of pride by being the family of a donor. In many countries, the citizens honor donors as heroes. In Korea, each hospital provides a commemorative space, which bears the name of the donor, while KODA also operates its own donor commemorative monitoring system. However, there are practical problems that have delayed the establishment of a national memorial park for donors as a place where citizens can be educated and honor them.

Currently, KODA has a family management team composed of social workers that provides a unified and diverse family support service through a family management manual. In cases where HOPO manages the deceased donors, a memorial event or donor commemorative space is prepared and managed according to each HOPO hospital's donor respect program.

(1) Family support during donation includes donor family support consultations, funeral procedure guidance and information, administrative procedure guidance and companion support service, funeral flower stands, booklet of condolences, etc. (2) Family management after donation includes telephone and visiting consultations, customized welfare guidance, connection to community resources for crisis situations, support for sadness, support for books dealing with grief, donor album production, administrative procedure guidance and pro- fessional institution accompaniment services. (3) Donor Honor and Remembrance celebrations include donor family reunions and donor memorial events. (4) Donor Transfer Support includes support for transfer to another funeral home after donation, if requested.

\section{CONCLUSION}

The most critical change in organ donations in 2018 is the continued decline in family consent. Although various causes exist, considerations that a negative view and the social atmosphere concerning life sharing are the biggest causes that hinder the sharing practice $[18,26]$. The concern is that this trend will continue. A shift in awareness is a time-consuming task that requires continuous education, national campaigning, and creation of a social atmosphere in which donors and their families receive respect from the public. At the same time, it is also necessary to revise the laws and the system to allow donation of organs or tissues from donors after circulatory deaths. In particular, it is time to consider actively legislating for first person authorization, which would result in family members' honoring the will of the deceased. Now, 20 years after the first enactment for organ donations, the person who holds the consent needs to be newly defined according to the changing social environment and family system. Education should also be considered in terms of organ procurement efficiency and civility with respect to the donor's willingness to donate. Above all, both the people and government should be aware that more than five people die each day due to the lack of organ donors, but can save lives of more than 4 patients every day if we have sufficient donors.

\section{ACKNOWLEDGMENTS}

\section{Conflict of Interest}

No potential conflict of interest relevant to this article was reported.

\section{ORCID}

Won-Hyun Cho https://orcid.org/0000-0001-5916-6601 


\section{REFERENCES}

1. Hart A, Smith JM, Skeans MA, Gustafson SK, Wilk AR, Robinson A, et al. OPTN/SRTR 2016 annual data report: kidney. Am J Transplant 2018;18 Suppl 1:18-113.

2. Shafer TJ, Wagner D, Chessare J, Schall MW, McBride $\mathrm{V}$, Zampiello FA, et al. US organ donation breakthrough collaborative increases organ donation. Crit Care Nurs Q 2008;31:190-210.

3. United Network for Organ Sharing. Data/transplant trends [Internet]. Richmond, VA: United Network for Organ Sharing; 2018 [cited 2019 Dec 20]. Available from: https://unos. org/data/transplant-trends.

4. Domínguez-Gil B, Danovitch G, Martin DE, López-Fraga M, Van Assche K, Morris ML, et al. Management of patients who receive an organ transplant abroad and return home for follow-up care: recommendations from the Declaration of Istanbul Custodian Group. Transplantation 2018;102: $2-9$.

5. International Summit on Transplant Tourism and Organ Trafficking. The declaration of Istanbul on organ trafficking and transplant tourism. Clin J Am Soc Nephrol 2008;3:1227-31.

6. International Registry in Organ Donation and Transplantation. Preliminary numbers 2018: IRODaT international registry in organ donation and transplantation [Internet]. Barcelona: International Registry in Organ Donation and Transplantation [cited 2019 Dec 20]. Available from: www. irodat. org.

7. Korea Organ Donation Agency. KODA annual report 2018. Seoul: Korea Organ Donation Agency; 2019.

8. Ministry of Health and Welfare. Related laws such as organs and human tissues in 2019. Sejong: Ministry of Health and Welfare; 2019.

9. Levin A. The impact of first-person consent legislation on the supply of deceased organ donors [thesis]. Allendale Charter Twp, MI: Grand Valley State University; 2014.

10. Traino HM, Siminoff LA. Attitudes and acceptance of First Person Authorization: a national comparison of donor and nondonor families. J Trauma Acute Care Surg 2013; 74:294-300

11. Callison K, Levin A. Donor registries, first-person consent legislation, and the supply of deceased organ donors. J Health Econ 2016;49:70-5.

12. Statistics Korea. Changes in death rates by major causes of death from annual report on the causes of death statistics 2018. Daejeon: Statistics Korea; 2018.

13. Lee J, Lee JG, Jung I, Joo DJ, Kim SI, Kim MS, et al. Development of a Korean liver allocation system using model for end stage liver disease scores: a nationwide, multicenter study. Sci Rep 2019;9:7495.

14. Park UJ, Kim MY, Kim HT, Cho WH. Validation of the KDRI in Korean deceased donor kidney transplantation. J Korean Soc Transplant 2014;28:78-82.

15. Yang JS, Gu TY, Lee JY, Yoon YS, Chung YI, Byun HS. Suggestions for improvement of the expanded category of kidney transplantation donor in Korea. Wkly Health Dis 2018;11:1231-7.

16. Siminoff LA, Alolod GP, Wilson-Genderson M, Yuen EYN, Traino HM. A comparison of request process and outcomes in donation after cardiac death and donation after brain death: results from a national study. Am J Transplant 2017; 17:1278-85.

17. Bernat JL, D' Alessandro AM, Port FK, Bleck TP, Heard SO, Medina J, et al. Report of a national conference on donation after cardiac death. Am J Transplant 2006; 6:281-91.

18. Center for Korean Network for Organ Sharing. Annual report of organ transplantation and tissue donation in 2018. Cheongju: Center for Korean Network for Organ Sharing; 2019.

19. Lee SH, Huh KH, Lee HS, Kim HJ, Kim MS, Joo DJ, et al. Waiting time for deceased donor kidney allocation in Korea: a single center experience. J Korean Soc Transplant 2012;26:32-7.

20. Ministry of Justice. Act on decisions on life-sustaining treatment for patients in hospice and palliative care or at the end of life (partially revised on Dec 2018. Act No. 15912). Gwacheon: Ministry of Justice; 2018.

21. Antoine C, Mourey F, Prada-Bordenave E; Steering committee on DCD program. How France launched its donation after cardiac death program. Ann Fr Anesth Reanim 2014;33:138-43.

22. Andrews PA, Burnapp L, Manas D; British Transplantation Society. Summary of the British Transplantation Society guidelines for transplantation from donors after deceased circulatory death. Transplantation 2014;97:265-70.

23. Manara AR, Murphy PG, O' Callaghan G. Donation after circulatory death. $\mathrm{Br} \mathrm{J}$ Anaesth 2012;108 Suppl 1: i108-21.

24. Summers DM, Johnson RJ, Allen J, Fuggle SV, Collett D, Watson CJ, et al. Analysis of factors that affect outcome after transplantation of kidneys donated after cardiac death in the UK: a cohort study. Lancet 2010;376:1303-11.

25. Sade RM. Brain death, cardiac death, and the dead donor rule. J S C Med Assoc 2011;107:146-9.

26. Lee WS. The influence of college students' social withdrawal on satisfaction with life: with emphasis on the mediating effect of aggression. Health Soc Welf Rev 2018;38:75-108. 